[0212-7199 (2006) 23: 11; pp 543-545] ANALES DE MEDICINA INTERNA Copyright @ 2006 ARAN EDICIONES, S.L.

AN. MED INTERNA (Madrid) Vol. 23, N. ${ }^{\circ} 11$, pp. 543-545, 2006

\title{
Linfoma de Burkitt abdominal en un adolescente
}

\author{
B. FLETA ASÍN, M. C. GONZALVO LIARTE, L. PALOMERA BERNAL ${ }^{1}$ \\ Servicios de Medicina Interna y ${ }^{1}$ Hematología. Hospital Clínico Universitario Lozano \\ Blesa. Zaragoza
}

ABDOMINAL BURKITT LYMPHOMA IN AN ADOLESCENT

\section{RESUMEN}

Se describe el caso clínico de un adolescente con un linfoma de Burkitt que debutó con dolor abdominal agudo. El tumor aumentó de tamaño rápidamente, se localizó mediante tomografía computarizada y se confirmó mediante estudio de la médula ósea. Se aplicaron dos protocolos quimioterápicos distintos, debido a la mala evolución, pero sin resultado satisfactorio. Se hacen unas consideraciones sobre el diagnóstico diferencial, especialmente con otros tumores primarios infantiles y procesos no neoplásicos.

PALABRAS CLAVE: Linfoma Burkitt. Linfoma no Hodgkin. Tumor abdominal. Cáncer.

\begin{abstract}
We report the case of a male adolescent affected by Burkitt Lymphoma which presented as acute abdominal pain and rapid growth mass. It was characterized by computed tomography and diagnose was confirmed by bone marrow study. Two different chemotherapic regimens were used because of unfavourable evolution, but they were not successful. We consider some other causes of abdominal bulky in childhood, especially primary tumours and non tumoural diseases.
\end{abstract}

KEY WORDS: Burkitt lymphoma. Non Burkitt lymphoma. Abdominal mass. Cancer.

Fleta Asín B, Gonzalvo Liarte MC, Palomera Bernal L. Linfoma de Burkitt abdominal en un adolescente. An Med Interna (Madrid) 2006; 23: 543-545.

\section{INTRODUCCIÓN}

Los tumores en la infancia y adolescencia constituyen la primera causa de mortalidad tras los accidentes e intoxicaciones. En la adolescencia uno de los tumores más frecuentes son los linfomas, y dentro de estos, los de tipo Burkitt representan sólo una mínima parte del total. Este tipo de linfomas se localiza preferentemente en macizo facial y abdomen y pueden producir distintos signos o síntomas en función de la localización, extensión de la tumoración y momento del diagnóstico (1). El pronóstico es incierto en gran parte de los casos. Comunicamos el caso de un adolescente afecto de linfoma de Burkitt abdominal de evolución fatal en un corto periodo de tiempo.

\section{CASO APORTADO}

Paciente de 16 años con antecedentes de neumonía en la lactancia y púrpura de Schönlein-Henoch, sin alergias medicamentosas ni toma de medicación habitual. Acude a Urgencias por pre- sentar desde hace 10 días dolor abdominal de intensidad creciente, de localización periumbilical al inicio que se generaliza posteriormente, junto con distensión y náuseas.

Se trata de un varón de raza blanca, normonutrido, con coloración e hidratación normales, consciente, orientado y reactivo. No se palpan adenopatías axilares, supraclaviculares ni cervicales. No se palpa bocio. Auscultación cardiaca y pulmonar normales. El abdomen es globuloso, doloroso difusamente a la palpación, con sensación de empastamiento en pared y matidez declive; no se palpan masas ni visceromegalias. Sucusión lumbar negativa. En extremidades inferiores (EEII) no hay edemas ni signos de trombosis venosa profunda, pulsos distales presentes y simétricos. Exploración neurológica normal. Impresiona de gravedad. En Urgencias se realizan hemograma, bioquímica, gasometría venosa, amilasas en sangre y orina, electrocardiograma y radiografía de tórax, en los que destaca leucocitosis de $13^{\prime} 7$ x $10^{\circ} / \mathrm{L}$ y plaquetas 421 x $10^{\circ} / \mathrm{L}$, siendo el resto normal.

Durante el ingreso el paciente sufre deterioro del estado general, con aumento rápido y progresivo del perímetro abdominal, edema de pared, disnea y edematización de genitales y EEII, aunque permanece estable hemodinámicamente. Precisa derivados mórficos para el control del dolor. Tras realización de ecografía, que muestra ascitis

Trabajo aceptado: 26 de mayo de 2006 
abundante multicompartimental, se procede a la realización de tomografía computarizada (TC) abdominal, donde se aprecia marcado engrosamiento peritoneal, grandes masas siguiendo el trayecto del mesenterio, con desplazamiento y atrapamiento de vasos y ascitis densa, todo ello compatible con mesotelioma peritoneal, metástasis o linfoma. El hígado, bazo, páncreas y riñones son normales (Figs. 1 y 2). Se realizan análisis de sangre más completos, en los que destaca leucocitosis: 14,2 × 10\%/L con desviación izquierda, hipoglucemia: $45 \mathrm{mg} / \mathrm{dL}$, hiperuricemia: $9,3 \mathrm{mg} / \mathrm{dL}$, aumento de reactantes de fase aguda: VSG $37 \mathrm{~mm}$, plaquetas $410 \times 10^{\%} / \mathrm{L}$, alfa 2 globulinas $17,7 \%$, fibrinógeno $605 \mathrm{mg} / \mathrm{dL}$, PCR: $35,7 \mathrm{mg} / \mathrm{dL}$, beta 2 microglobulina: $3,2 \mathrm{mcg} / \mathrm{mL}, \mathrm{LDH}: 1689 \mathrm{UI}$, adenosindeaminasa: 22`3 U/L, aumento de marcadores tumorales (enolasa, CA. 125, CIFRA 21). Inmunoelectroforesis: gammapatía monoclonal IgM kappa. Estudio inmunitario: IgG 874 mg/dL, IgA 228 mg/dL, IgM 254 mg/dL. Serología VEB IgM negativo.

Seguidamente se realiza punción abdominal mediante radiología intervencionista con toma de muestra tumoral y líquido ascítico, de aspecto lechoso, que son valorados por el Servicio de Anatomía Patológica, Microbiología y Hematología, que emite el diagnóstico de linfoma de Burkitt. El paciente se traslada al servicio de Hematología y se inicia tratamiento quimioterápico urgente con protocolo Hyper-CVAD (Ciclofosfamida, Vincristina, Doxorubicina y altas dosis de Metotrexate y Citarabina), previa preparación del paciente

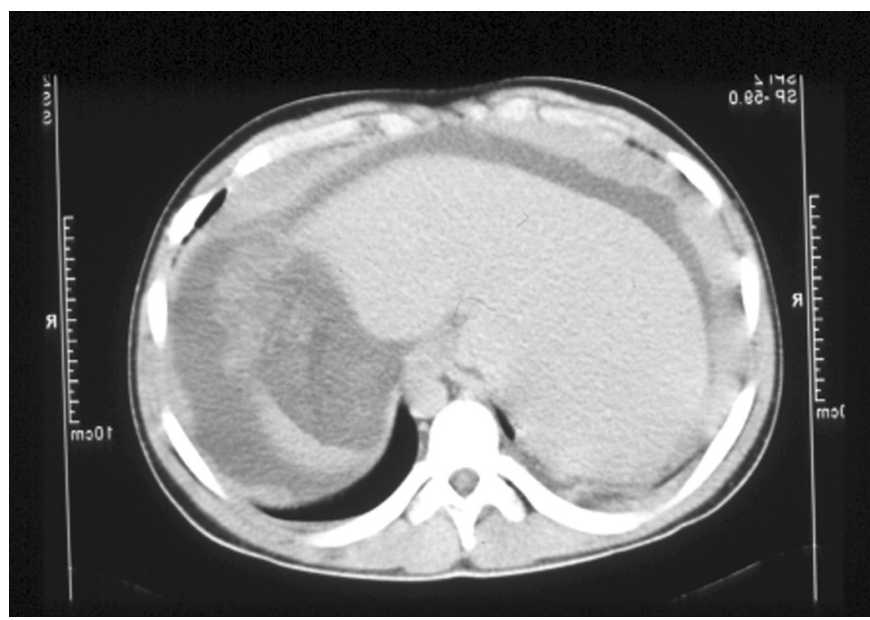

Fig. 1. Imagen tomográfica abdominal en la que se observa marcado engrosamiento peritoneal y ascitis.

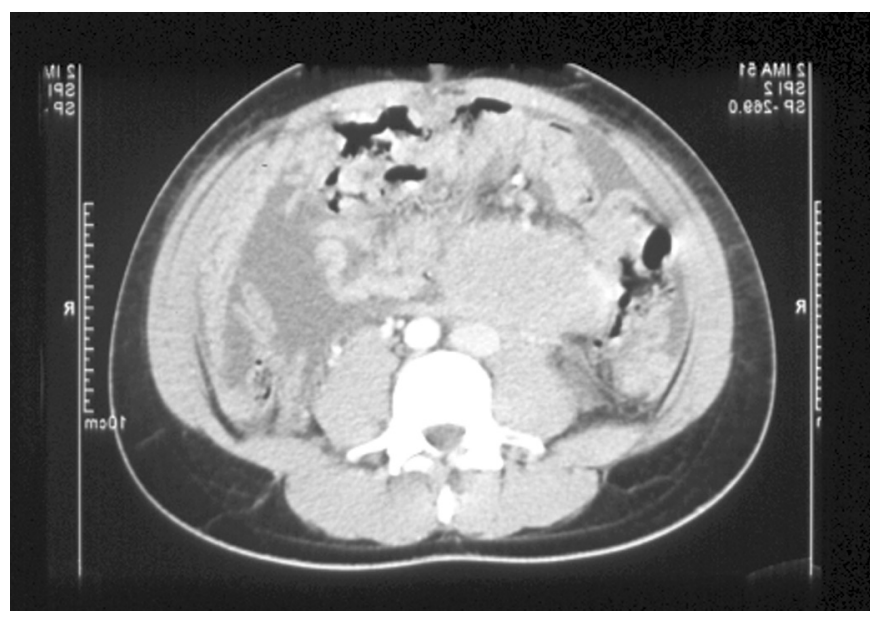

Fig. 2. Imagen tomográfica abdominal en la que se observan grandes masas con desplazamiento y atrapamiento de vasos, y ascitis. para evitar el síndrome de lisis tumoral con medidas habituales y rasburicasa $\left(\right.$ Fasturtec $\left.^{\oplus}\right)$. Se realiza aspirado medular, donde se objetiva afectación masiva por linfoma de Burkitt. Se realiza cariotipo, que es normal, y análisis de la médula ósea del paciente mediante fluorescencia (FISH) con el hallazgo de la translocación $\mathrm{t}(8,14)$ (q24; q32) en el 7'5\% de las células.

El paciente es dado de alta hospitalaria y sometido a dos nuevos ciclos de tratamiento quimioterápico y preventivo de lisis tumoral, con buena respuesta inicial. Ingresa unas semanas después por empeoramiento del estado general, con dolor difuso, aumento de nuevo del perímetro abdominal y pancitopenia. Tras nuevos TC y aspirado medular se evidencia progresión del linfoma en peritoneo, retroperitoneo y médula, por lo que se decide cambio en el protocolo quimioterápico, a pesar de lo cual se produce deterioro clínico con disnea progresiva, taquicardia y oliguria, con mala respuesta al tratamiento de soporte. Se decide traslado a UCI, donde se aplica quimioterapia de rescate y tratamiento intensivo, sin respuesta satisfactoria, falleciendo el paciente.

\section{DISCUSIÓN}

El linfoma de Burkitt (LB) es una neoplasia fundamentalmente infantil, aunque también puede presentarse en la edad adulta, especialmente en individuos inmunodeprimidos. Desde los 15 a los 19 años, los linfomas representan el $27 \%$ de todos los tumores primarios, seguidos de las leucemias (16\%), tumores de ovario/testículo (11\%) y del sistema nervioso central (10\%). Dentro de los linfomas, en pacientes de esta edad, el de tipo no Hodgkin representa el $57 \%$ de los casos y de estos, sólo la tercera parte son linfomas Burkitt (1).

Pueden diferenciarse distintas formas clínicas y epidemiológicas. La forma endémica o africana se asocia de forma casi generalizada (95 a $100 \%$ de los casos) a la presencia de genoma del virus de Epstein Barr (VEB) en las células tumorales. Fue descrito en 1958 por Dennis Burkitt, un cirujano inglés que trabajaba en Uganda. Su relación con el VEB se estableció posteriormente en 1964 cuando Achong y Barr identificaron mediante microscopía electrónica partículas víricas en linfoblastos cultivados de pacientes afectos (2-4). El mecanismo patogénico no está del todo aclarado, pero al parecer el VEB estimularía la proliferación de linfocitos B y alteraría su propio genoma. Se ha sugerido la participación del plasmodium (agente productor de la malaria) en el desarrollo del linfoma, pues comparte área de endemicidad con el linfoma de Burkitt, y al igual que el VEB se comportaría como mitógeno, favorecedor de la proliferación de linfocitos Se localiza principalmente en mandíbula, órbita y médula espinal (5).

El tipo esporádico, descrito en Estados Unidos y Europa, se asocia en $10-20 \%$ de los casos al VEB, y suele presentarse con síntomas abdominales como dolor, náuseas, vómitos y masa a la exploración (5). Se ha descrito también la presencia de ascitis, útil para el diagnóstico, y en ocasiones, cuadros localizados en íleon que se presentan como invaginación de evolución subaguda que podrían curarse con intervención quirúrgica, aunque lo más habitual es que la afectación sea más difusa, como en mesenterio, retroperitoneo y ganglios. En raras ocasiones este trastorno se presenta como una leucemia aguda de células de Burkitt circulantes (LLA-L·), frecuente sobre todo en afectos de $\operatorname{SIDA}(6,7)$.

La mayor parte de los LB poseen células de inmunofenotipo B y una translocación que disregula el gen c-myc, relacionado con la transcripción de proteínas implicadas en la regulación del ciclo celular, apoptosis, crecimiento, dife- 
renciación y adhesión. El ejemplo más llamativo es la translocación $\mathrm{t}(8,14)$, presente en el $80 \%$ de los casos de LB, en que el brazo largo del cromosoma 8 que contiene el gen cmyc se traslada al cromosoma 14 a la zona del gen de las cadenas pesadas de las inmunoglobulinas. Al parecer, el punto de ruptura genético tiene distinta localización en los tipos endémico y esporádico. En el 20\% restante aparecen translocaciones entre los cromosomas 8 y $2, \mathrm{t}(2,8)$ (gen de las cadenas ligeras kappa) y 8 y $22, \mathrm{t}(8,22)$ (gen de las cadenas ligeras lambda) $(5,8)$.

En caso de afectación abdominal es preciso el diagnóstico diferencial con otras neoplasias primarias infantiles como el tumor de Wilms, neuroblastoma o tumor neuroectodérmico periférico, aunque han de considerarse otros procesos no leucémicos ni linfomatosos, como adenocarcinoma de ciego e ileon terminal, enfermedad de Crohn, leiomiosarcoma o incluso un absceso abdominal. Como neoplasia que infiltra médula ósea, conviene diferenciarlo de leucemias de precursor B y $\mathrm{T}$ y mieloides. A nivel periférico es preciso distinguirlo del linfoma difuso de células grandes B $(7,9)$.

El pronóstico se ha relacionado con la carga tumoral, estadío, infiltración de LCR y médula ósea, cifra de LDH, presencia de anemia y blastos circulantes. La titulación de anticuerpos frente al VEB podría tener implicaciones pronósticas según algunos estudios. Los pacientes más jóvenes suelen tener respuestas más favorables, pero esto último no se ha confirmado $(5,8)$.

No existe una única opción de tratamiento quimioterápico para este tipo de linfomas. Un aspecto importante es la prevención del síndrome de lisis tumoral, producido por destrucción de gran cantidad de células tumorales caracterizado por hiperuricemia, hipercaliemia e hiperfosfatemia con hipo- calcemia, que puede inducir insuficiencia renal. Para ello será preciso hidratar convenientemente, alcalinizar la orina y administrar alopurinol antes de la quimioterapia. En casos extremos se requiere diálisis $(5,6)$.

Actualmente el tratamiento quimioterápico consiste en regímenes intensivos de corta duración que incluyen agentes como ciclofosfamida, vincristina, metotrexate, doxorubicina y citarabina, que consiguen supervivencias de 2 años libres de enfermedad en el 75 al $89 \%$ de los pacientes pediátricos con LB de estadío avanzado, con porcentajes menores en adultos. El tratamiento se complementa con profilaxis frente a las infecciones y la afectación del sistema nervioso central, y factores estimuladores de colonias. Las recaídas ocurren generalmente el primer año, y son signo de especial mal pronóstico. La estrategia terapéutica a seguir en estos casos no está consensuada. El trasplante alogénico de progenitores hematopoyéticos podría ser una alternativa, aunque su éxito no se ha confirmado (8).

De los diez casos de linfomas Burkitt diagnosticados en nuestro hospital en los últimos doce años, sólo dos eran adolescentes, ambos de 16 años y varones. Los ocho pacientes restantes, dos varones y seis mujeres, tenían una edad de 29 a 70 años (media de 43,1 años). Aunque el caso presentado no es excepcional, presenta la característica de que su evolución ha sido rápidamente progresiva. El paciente fue diagnosticado y tratado con arreglo a los protocolos descritos, sin embargo, no respondió satisfactoriamente a la terapia. El hallazgo de células tumorales características en el líquido ascítico y la existencia de translocación genética en médula ósea, confirman el diagnóstico. Hasta entonces, es preciso considerar el diagnóstico diferencial en pacientes de esta edad, con los procesos anteriormente mencionados.

\section{Bibliografía}

1. Gurney JG, Bondy ML. Epidemiología del cancer en niños y adolescents. En: Behrman RE, Kliegman RM, Jenson HB, editores. Nelson. Tratado de Pediatría. 17 ed. Madrid: Elsevier; 2004. p. 1679-1681.

2. Okano M. Epstein-Barr virus infection and its role in the expanding spectrum of human diseases. Acta Pediatr 1998; 87: 11-18.

3. Joske D, Knecht H. Epstein-Abrr Virus in lymphomas: a review. Blood Reviews 1993; 7: 215-222.

4. Young LS, Murray PG. Epstein-Barr virus and oncogenesis: from latent genes to tumours. Oncogene 2003; 22: 5108-5121.

5. Molina FJ. Linfomas no Hodgkin. En: Madero L, Muñoz A, editores Hematología y Oncología Pediátricas. $1^{a}$ ed. Madrid: Ediciones Ergon
S.A.; 1997. p. 447-466.

6. Prats J, Sánchez de Toledo J. Linfoma no Hodgkin en la infancia. En: Sierra L, Calvo F, Villa-Elizaga I, Cañadell J, editores. Oncología Pediátrica. $1^{\mathrm{a}}$ ed. Madrid: Interamericana McGraw-Hill; 1992. p. 371-405.

7. Shipp MA, Mauch PM, Harris NL. Linfomas no Hodgkin. En: De Vita VT, Hellman S, Rosemberg SA, editores. Cáncer. Principios y Práctica de Oncología. $5^{\text {a }}$ ed. Madrid: Panamericana; 2000. p. 2164-2220.

8. Blum KA, Lozanski G, Byrd JC. Adult Burkitt leukemia and lymphoma. Blood 2004; 104: 3009-19.

9. Carreira C, Gómez MN. Masa abdominal en un varón de trece años. Rev Clin Esp 1990; 186: 141-2. 